\title{
Ankilozan Spondilitli Bir Hastada Strongyloides stercoralis: Olgu Sunumu
}

\author{
Strongyloides stercoralis in a Patient with Ankylosing Spondylitis: Case Report
}

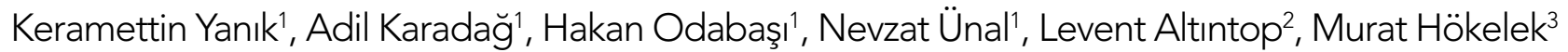 \\ 'Ondokuz Mayıs Üniversitesi Tıp Fakültesi, Tıbbi Mikrobiyoloji Anabilim Dalı, Samsun, Türkiye \\ ${ }^{2}$ Ondokuz Mayıs Üniversitesi Tıp Fakültesi, İç Hastalıkları Anabilim Dalı, Samsun, Türkiye \\ ${ }_{3}^{3}$ stanbul Üniversitesi Cerrahpaşa Tıp Fakültesi, Tıbbi Mikrobiyoloji Anabilim Dalı, İstanbul, Türkiye
}

\section{ÖZET}

Strongyloidosis, farklı birkaç Strongyloides türünün neden olduğu nematod kaynaklı bir hastalıktır. Bu olgu çeşitli şikayetler ve klinik bulgularla gelen immun süprese hastalarda Strongyloidosis'e dikkat çekmek amacıyla sunulmuştur. Yirmibeş yıldır Ankilozan Spondilit tanısıyla izlenen ve uzun süre kortikosteroid kullanmış olan 55 yaşında erkek hasta, son beş yıldır infliximab tedavisi almaktaydı. On gündür devam eden sağ ayakta şişlik, sol omuzda tutukluk, bel ağrısı şikayetleri ile başvuran hastanın tetkiklerinde anemi varlığı dikkati çekmiştir. Endoskopik duedonum biopsi örneğinin patolojik incelemesinde S. stercoralis larvası görüldüğü rapor edilmiş̧tir. Periferik yaymasında \%68,4 nötrofil, \%17 lenfosit, \%7,5 monosit ve \%6,7 (normal \%2-6,2) eozinofil görülmüştür. lgE düzeyi 285IU/mL (normal 5-120IU/mL) yüksek tespit edilmiştir. Üç kez alınan dışkının nativ-lugol ve formaldehit eter çöktürme yöntemi ile incelenmesinde yoğun olarak S. stercoralis larvası saptanmıştır. Ancak iki kür 7 gün süre ile $400 \mathrm{mg} /$ gün dozunda albendazole tedavisi önerisi ile dışkıda S. stercoralis larvası tespit edilmemiştir. Tedaviye yanıtın ilk kürde görülmemesi ve ikinci kürde iyileşmenin sağlanması dikkat çekici özelliklerdir. Klinisyenlerin, çeşitli yakınmalarla başvuran, özellikle bağışıkık sistemi baskılanmış hastaların, tanı ve tedavisinde hiperenfeksiyon olasılığını göz önünde bulundurmalarının, bu nematod'un ciddi ölümcül olabilecek sonuçlarını önlemede etkili olacağı düşüncesindeyiz. (Turkiye Parazitol Derg 2013; 37: 143-6)

Anahtar Sözcükler: Strongyloides stercoralis, ankilozan spondilit, immunsupresyon

Geliş Tarihi: 24.02.2013

Kabul Tarihi: 14.04.2013

\section{ABSTRACT}

Strongyloidiasis is a nematode-borne disease caused by several Strongyloides species. This case was presented in order to indicate Strongyloidosis in immunocompromised patients with several clinical findings. A fifty-five year old male patient on corticosteroid medication for a long time because of ankylosing spondylitis was on infliximab medication for 5 years. He presented with swelling of his right foot for ten days, right shoulder stiffness and low back pain. The presence of anaemia was remarkable. S. stercoralis was reported in histological examination of endoscopic duodenal biopsy specimen. Peripheral blood smear showed $68.4 \%$ neutrophils, $17 \%$ lymphocytes, $7.5 \%$ monocytes, and $6.7 \%$ (normal range $2 \%-6.2$ ) eosinophils. The level of IgE was raised: $285 \mathrm{IU} / \mathrm{mL}$ (normal range $5-120 \mathrm{IU} / \mathrm{mL}$ ). A large number of $S$. stercoralis larvae were detected upon stool examination with saline and iodine mounts and the formaldehyde ether concentration method. After treatment with two cure albendazole $400 \mathrm{mg} /$ day for 7 days, S. stercoralis larvae were not detected in stool examination. It is interesting that response to treatment was not observed on the first cure and the recovery was seen on the second cure. We suggest that hyperinfections should be taken into consideration in the diagnosis and treatment of immunocompromised patients with several complaints so that life-threatening effects of the nematode may be prevented. (Turkiye Parazitol Derg 2013; 37: 143-6)

Key Words: Strongyloides stercoralis, Ankylosing Spondylitis, immunosuppression

Received: 24.02.2013

Accepted: 14.04 .2013

Bu çalışma 3-7 Kasım 2012 tarihlerinde Aydın'da düzenlenen 35. Türk Mikrobiyoloji Kongresi'nde poster bildiri olarak sunulmuştur. This study was presented as a poster paper at 35 th Turkish Microbiology Congress, 3-7 November 2012 - Aydın, Turkey.

Yazışma Adresi / Address for Correspondence: Dr. Nevzat Ünal, Ondokuz Mayıs Üniversitesi Tıp Fakültesi, Tıbbi Mikrobiyoloji Anabilim Dalı, Samsun, Türkiye Tel: +90 3623121919 E-posta: drnevzatunal@hotmail.com

doi:10.5152/tpd.2013.31 


\section{GiRiş}

Strongyloidosis, farklı birkaç Strongyloides türünün neden olduğu nematod kaynaklı bir hastalıktır. Dünyada yaklaşık 30-100 milyon civarında kişi enfektedir (1). Strongyloidosis'in en sık etkeni Strongyloides stercoralistir, Bu nematod genellikle sıcak ve ılıman iklimlerde görülür nadiren soğuk bölgelerde de rastlanmaktadır. Strongyloides stercoralis insana sıklıkla toprakta filariform larvaların sağlam deriden vücuda girmesi ile bulaşır. Larvalar kan dolaşımı ile akciğerlere, oradan trakea ve farenkse geçerek yutulur. Duedonum ve jejunumun üst kısım mukozasına girerek, gelişimini iki haftada tamamlar ve dişileri, içinde larva bulunan yumurta üretmeye başlar. Enfekte kişiler dışkıları ile rabditidoform larva çıkarırlar. Larvalar dış ortamdaki evrimleri sonucu enfektif form olan filariform larva haline dönüşürler. S. stercolaris bir jeohelminttir ve yaşam döngüsünü tamamlayabilmek için mutlaka larvaların toprağa ulaşması gerekmektedir. Yaşam döngüsü karmaşıktır. Parazitin düz, çapraşık ve otoenfeksiyon şeklinde üç farklı yaşam döngüsü olabilir. Düz evrimde, dışkı ile atılan rabditiform larva toprakta filariform larva haline dönüşür ve deriden insan vücuduna girer. Çapraşık evrimde parazit toprakta özgür yaşayan erkek ve dişilere dönüşerek bir veya birkaç nesil özgüryaşadıktan sonra parazitikforma dönebilir. Otoenfeksiyonda parazit yaşam döngüsünün tüm aşamalarını insan vücudunda tamamlayıp çeşitli klinik tablolarla seyredebilir. Barsak lümenindeki rabditiform larvalar barsak mukozasına girerek evrimini tamamlar ve filariform larva haline geçer ve konağı tekrar enfekte eder (2). Otoenfeksiyon kronikleşebilir, özellikle hipogammagloblunemi, HIV, Cushing sendomu, antikanser kemoterapisi, immun süprese tedavi alanlar gibi bağışıklık sistemi baskılanmış hastalarda hayatı tehdit eden hiperenfeksiyonlara neden olabilir $(3,4)$. Tanı klinik bulgular ile birlikte dışkıda rabditiform larvaların veya yumurtaların, duedonum sıvisı ve balgam incelemesinde larvaların gösterilmesi ile konur. Tanıda agar plak kültürlerinin duyarlılığı yüksektir (5). Rutinde kullanılmamakla birlikte ELISA, immunsorbent assay, immunblot yöntemleri tanı ve tedavi takibinde kullanılmaktadır. Tedavide albendazol $400 \mathrm{mg}$ üç gün veya ivermektin 200 mg/kg/gün iki gün süre ile önerilmektedir (6). Bu olgu genel olarak karın ağrısı, diyare, kilo kaybı ve halsizlik şikayetleri ve çeşitli klinik bulgularla gelen immun süprese hastalarda Strongyloidosis'e dikkat çekmek amacıyla sunulmuştur.

\section{OLGU SUNUMU}

Yirmibeş yıldır Ankilozan Spondilit tanısıyla izlenen ve uzun süre kortikosteroid tedavisi almış olan 55 yaşında erkek hasta, son beş yıldır Dahiliye Romatoloji polikliniği önerisi ile infliximab tedavisi almaktaydı. On gündür devam eden sağ ayakta şişlik, sol omuzda tutukluk, bel ağrısı şikayetleri ile Fizik Tedavi ve Rehabilitasyon polikliniğine başvuran hastanın yapılan tetkiklerinde anemi varlığı dikkati çekmiştir. Dahiliye kliniği tarafından anemi etyolojisini araştırmak için uygulanan endoskopi ile duedonumdan alınan biopsi örneğinin patolojik incelemesinde S. stercoralis larvası görüldüğü rapor edilmiştir.

Özgeçmişinde, hasta 30 yıl ayakkabı mağazasında, son 5 yıldır da kendi bahçesinde çalışmıştır. Hastanın ankilozan spondilit'e bağlı şikayetleri dışında Strongyloidosis'i düşündürecek diyare, karın ağrısı, inatçı öksürük gibi şikayetleri bulunmamaktadır. Hastanın hikayesinde 30 yıllık evli ve 2 çocuğunun olduğu, ailesinde ben- zer hastalığı düşündürecek şikayetlileri olan kişilerin olmadığı öğrenilmiştir.

Fizik incelemede; ateş $37^{\circ} \mathrm{C}$, nabız $65 / \mathrm{dk}$, tansiyon arteriyel 110/70 mmHg.

Hastanın tam kan sayımında beyaz küre 12,42 bin/uL, Hb: 9,10 g/ dL, Htc: \%29, trombosit: 567.000/uL, periferik yaymasında \%68,4 nötrofil, \%17 lenfosit, \%7,5 monosit ve \%6.7 (normal \%2-6,2) eozinofil görülmüştür. CRP 94,8 mg/L, sedimantasyon $82 \mathrm{~mm} /$ saat, total protein $7,7 \mathrm{~g} / \mathrm{dL}$, albümin $4 \mathrm{gr} / \mathrm{dL}$ ve $\mathrm{g}$ E düzeyi $285 \mathrm{IU} /$ $\mathrm{mL}$ (normal 5-120 IU/mL) tespit edilmiştir. Gaitanın mikroskopik incelemesinde her sahada $S$. stercoralis larvası görülmüştür Üç kez alınan dışkının nativ-lugol ve formaldehit eter çöktürme yöntemi ile incelenmesinde yoğun olarak S. stercoralis larvası saptanmıştır (Şekil 1-3). Anti HIV negatif, HBs Ag negatif, Anti HCV negatif, diğer tüm biyokimyasal parametleri, akciğer filmi, ventilasyon perfüzyon sintigrafisi ve batın USG'si normal sınırlarda bulunmuştur.

Hastaya 7 gün süre ile 400 mg/gün dozunda albendazole tedavisi önerilmiştir. Tedavinin sonunda incelenen dışkı örneğinde

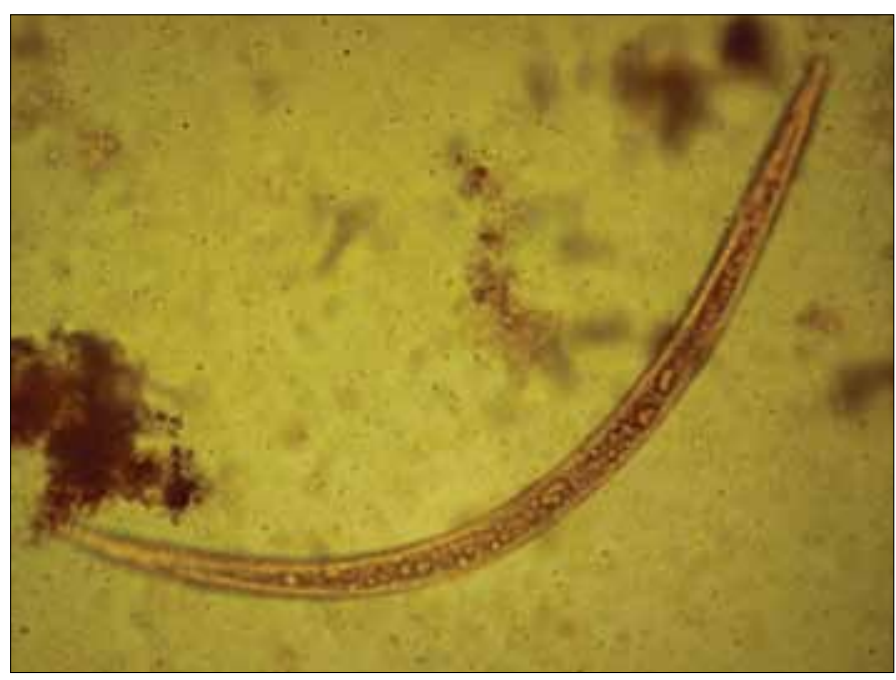

Şekil 1. Nativ-lugol yöntemi ile yapılan dışkı incelemesinde saptanan S. stercoralis rabditiform larvası

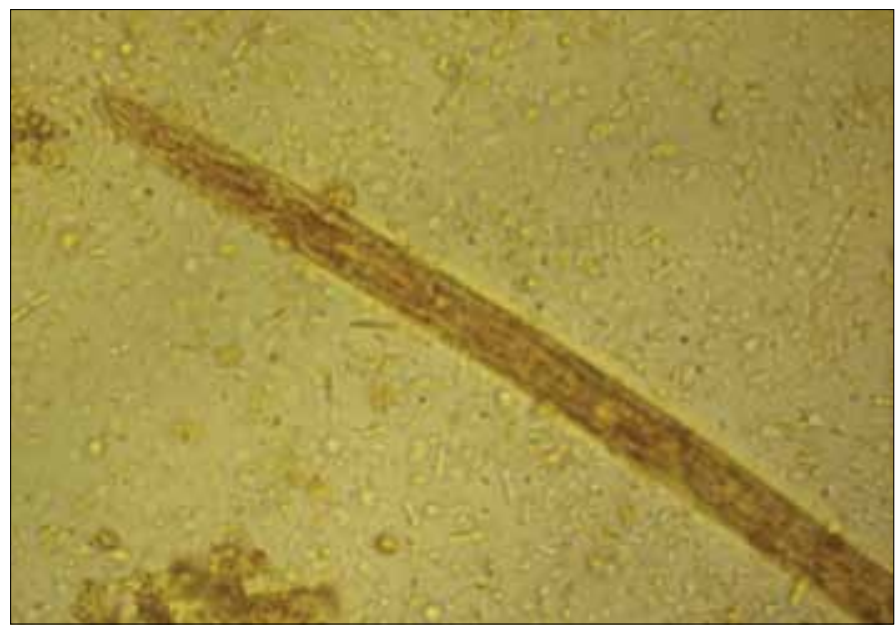

Şekil 2. Nativ-lugol yöntemi ile yapılan dışkı incelemesinde saptanan S. stercoralis rabditiform larvasının ağız bölümü 


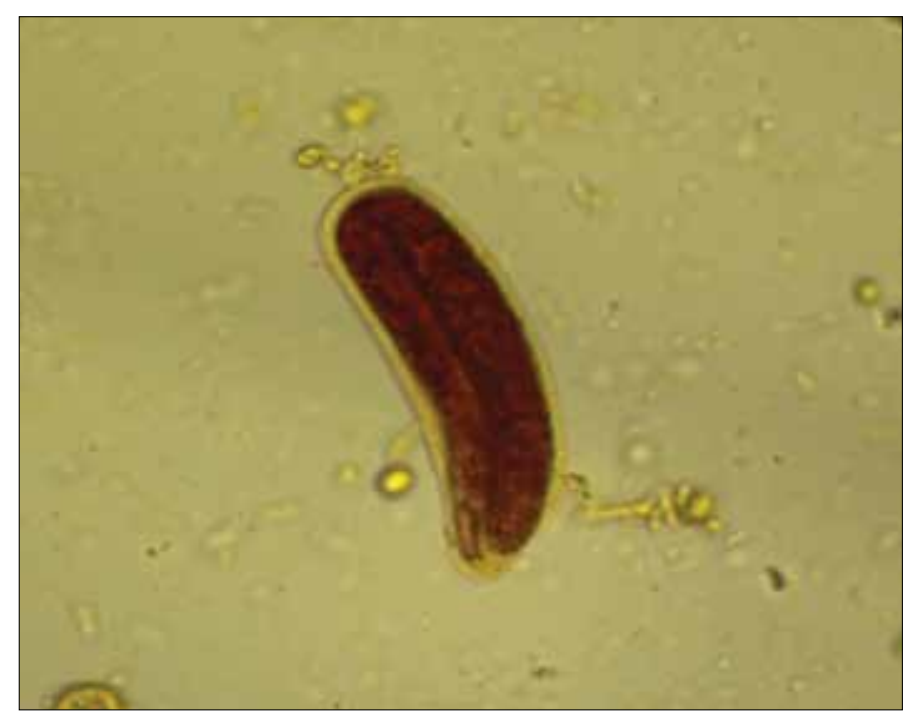

Şekil 3. Nativ-lugol yöntemi ile yapılan dışkı incelemesinde saptanan S. stercoralis larvası

S. stercoralis larvalarına rastlanmamıştır. Fakat tedavinin başlangıcından sonraki 30. günde kontrol amacıyla yapılan dışkı incelemesinde S. stercoralis larvalarının görülmesi üzerine tekrar 7 gün süre ile albendazole tedavisi önerilmiştir. Tedavinin sonunda 30. günde ve 40. Günde dışkı örneğinin nativ-lugol ve formaldehit eter çöktürme yöntemi ile incelenmesinde $S$. stercoralis larvası tespit edilmemiştir.

\section{TARTIŞMA}

Strongyloid larvalarla karşılaşmayı kolaylaştıran faktörler arasında, çiftçilik gibi toprakla teması gerektiren meslekler ve yaşam koşulları başta gelmektedir. Strongyloidosis genellikle asemptomatik seyretmekle birlikte bazen deri, akciğer ve barsaklara ait değişik klinik semptomlar gözlenebilir. Genel olarak şikayetler karın ağrısı, diyare, kilo kaybı ve halsizliktir $(5,7)$. Eozinofil sayısı etkilenen kişilerin \%70'inde, hastalığın başlangııında yüksek iken ilerleyen dönemlerde azalarak \%5-15 oranında ılımlı bir seyir gösterir $(8,9)$. Bu olguda strongyloidosis tanısı öncesi eozinofil sayısı \%3-10,1 oranları arasında seyretmiş olup tedavi sonrası normal düzeye gerilemiştir. Enfeksiyonun erken döneminde polimorfonükleer lökosit ve total IgE düzeyinin yüksek olduğu bildirilmektedir (5). Bu olguda da IgE düzeyi yüksek bulunmuştur. S. stercoralis'in yaşam döngüsünde gaita ile atılan rabditiform larvalar toprakta enfektif form olan filariform larvaya dönüşür. S. stercoralis'in larvaları, kancalı kurt larvaları ile karışabilir ayrımı tanı ve tedavi açısından önemlidir. Kancalı kurt larvasında bukkal kavite uzun iken S. stercoralis larvasında kısadır ve genital primordiumlar S. stercoralis'de kancalı kurtlara göre daha büyüktür (10).

Ülkemizde ve dünyada yapılan birçok çalışmada bağışıklık sistemi baskılanmış hastalarda strongyloidosis olguları rapor edilmiştir $(11,12)$. Turhan ve ark. (13) İmmun hemolitik anemi tanısı ile kısa süreli steroid kullanan 20 yaşında erkek hastada saptadıkları strongyloidosis olgusunun albendazol kullanımı ile başarılı bir şekilde tedavi edildiğini bildirmişlerdir.

Moghaddam ve ark. (14) 45 yaşında bir bayan hastanın, ülseratif kolit tedavisi için iki yıldır 10 mg/gün oral prednizolon kullanmak- ta iken gelişen strongyloidosis olgusunun 10 gün süre ile 800 mg/gün albendazol kullanılarak tedavi edildiğini bildirmişlerdir.

Win ve ark. (15) Non-Hodgkin lenfoma tanısı ile kemoterapi almakta olan 62 yaşında erkek hastada plevral efüzyon gelişmesi üzerine alınan torasentez sıvısında ve gaitanın direkt mikroskobik incelemesinde rabditiform larva saptamışlar ve kanser kemoterapisi alan bağışıklık sistemi baskılanmış hastaların hiperenfeksiyon tablosu ile gelebileceğinin akılda tutulması gerektiğini bildirmişlerdir.

Lessnau ve ark. (16) epigastrik ağıı ve ishal şikayetleri ile başvuran 60 yaşında iki yıldır HIV seropozitif erkek hastada endoskopik biyopsi ile duedonumda $S$. stercoralis larvası tespit etmişlerdir. Tedavide üç gün süre ile $50 \mathrm{mg} / \mathrm{kg} / \mathrm{gün}$ tiabendazol kullanılmasına rağmen hasta kaybedilmiştir. Otopside gastrointestinal kanal, karaciger, dalak ve kalp dokusunda S. stercoralis larvası tespit edilmiştir. Çalışmalarının sonunda HIV pozitif hastalarda dissemine hiperenfeksiyon riskinin yüksek olduğuna, IgE ve eozinofil düzeyinin düşük, standart tedavinin de başarısı olabileceğine dikkat çekmişlerdir.

Keiser ve ark.'nın (17) immün sistemi baskılanmış populasyonda S. stercoralis enfeksiyonlarını inceledikleri çalışmalarında; Bağışıklık sistemini baskılayan çeşitli durumlardan (immun supresif ilaç kullanımı, HTLV-1 enfeksiyonu, HIV enfeksiyonu, hematolojik maligniteler, organ nakli, hipogamaglobulinemi, malnütrisyon ve ilişkili durumlar vb.) en sık steroidler ve HTLV-1 enfeksiyonunun kronik strongyloidosis ve hiperenfeksiyon ile ilişkili olduğunu bildirmişlerdir.

Lim ve ark. (18) Kanada'da komplike ve fatal strongyloidosis enfeksiyonlarında risk faktörlerini, tanı ve tedaviyi inceledikleri çalışmalarında, steroid kullanımı ve HTLV-1 enfeksiyonunu en önemli risk faktörleri olarak bildirmişlerdir.

Newberry ve ark. (19) çalışmalarında dokuz hastada kortikosteroid tedavisi sırasında srongyloidosis görüldüğ̈̈ ve akut solunum yetmezliği, astım atağı veya pulmoner embolizm ile hiperinfeksiyon tablosu ve ölümcül de olabilen ciddi komplikasyonların geliştiğini bildirmişlerdir.

Bazı çalışmalarda bağışıklık sistemi normal kişilerde de strongyloidosis olgusu rapor edilmiştir (20-22).

\section{SONUÇ}

S. stercoralis tedavisinde ilk tercih albendazoldür. Komplike vakalarda tedavinin uzatılması yada ivermektin ile kombine edilmesi önerilmektedir. Bizim olgumuz ankilozan spondilit tanısı ile uzun süre immun suprese ilaç alan bir hastada gelişen S. stercoralis enfeksiyonudur. Tedaviye yanıtın ilk kürde görülmemesi ve ikinci kürde iyileşmenin sağlanması dikkat çekici özelliklerdir. Strongyloidosis erken tanı ve uygun tedavi ile mortalitenin azaltılabileceği, tedavi edilebilir bir hastalıktır. Klinisyenlerin, çeşitli yakınmalarla başvuran, özellikle bağışıklık sistemi baskılanmış hastaların, tanı ve tedavisinde hiperenfeksiyon olasılı̆ıını göz önünde bulundurmalarının, bu nematod'un ciddi ölümcül olabilecek sonuçlarını önlemede etkili olacağı düşüncesindeyiz. 


\section{Çıkar Çatışması}

Yazarlar herhangi bir çıkar çatışması bildirmemişlerdir.

Hakem değerlendirmesi: Dış bağımsız.

\section{Yazar Katkıları}

Fikir - M.H., L.A.; Tasarım - M.H., A.K.; Denetleme - M.H., A.K.; Kaynaklar - L.A., H.O.; Malzemeler - K.Y., H.O.; Veri toplanması ve/veya işlemesi - N.Ü., K.Y.; Analiz ve/veya yorum - M.H., L.A.; Literatür taraması - A.K., N.Ü.; Yazıyı yazan - A.K., N.Ü.; Eleştirel inceleme - M.H., L.A.; Diğer - K.Y., N.Ü.

\section{Conflict of Interest}

No conflict of interest was declared by the authors.

Peer-review: Externally peer-reviewed.

\section{Author Contributions}

Concept - M.H., L.A.; Design - M.H., A.K.; Supervision - M.H., A.K.; Funding - L.A., H.O.; Materials - K.Y., H.O.; Data Collection and/or Processing - N.Ü., K.Y.; Analysis and/or Interpretation M.H., L.A.; Literature Review - A.K., N.Ü.; Writing - A.K., N.Ü.; Critical Review - A.K., N.Ü.; Other - K.Y., N.Ü.

\section{KAYNAKLAR}

1. Akbulut A. Nematodlar. Topcu AW, Soyletir G, Doğanay M (editörler). Enfeksiyon Hastalıkları ve Mikrobiyolojisi Nobel Tıp Kitabevleri 3. baskı istanbul 2008.p.2602-16.

2. Akısü Ç. Strongyloidosis. Ozcel MA (editör). Tıbbi Parazit Hastalıkları. Turkiye Parazitoloji Derneği Yayın 2007; 22.s.757-67.

3. Concha R, Harrington WJ, Rogers A. Intestinal strongyloidosis: recognition, management and determinants of outcome. J Clin Gastroenterol 2005; 39: 203-11. [CrossRef]

4. Goh SK, Chow PK, Chung AY, Tan BH, Tan PH. Strongyloides colitis in a patient with Cushing's syndrome. Gastrointest Endosc 2004; 59: 738-41. [CrossRef]

5. Garcia LS. Diagnostic Medical Parasitology. $5^{\text {th }}$ Edition. Washigton DC: American Society for Microbiology 2007.p.271-80.

6. Maguire JH. Intestinal Nematodes (Roundworms). Mandell GL, Bennett JE, Dolin R (eds). $7^{\text {th }}$ Ed. Mandell, Douglas and Bennett's Principles and Practice of Infectious Diseases.Philadelphia: Elsevier 2009.p.3577-86.

7. Siddiqui AA, Berk SL. Diagnosis of Strongyloides stercoralis infection. Clin Infect Dis 2001; 33: 1040- 7. [CrossRef]

8. Junod C. Retrspective study of 1934 cases of strongyloidosis in Paris (1970-1986). II. Diagnosis, Eosinophilia. Treatment. Bull Soc Pathol Exot Filiales 1987; 80: 370-82.
9. Loutfy MR, Wilson M, Keystone JS, Kain KC. Serology and eosinophil count in the diagnosis and management of strongyloidiasis in a non-endemic area. Am J Trop Med Hyg 2002; 66: 749-52.

10. Hökelek M. Sünbül M. Kaya N. Ülseratif kolitli bir hastada Entamoeba histolytica ve Strongyloides stercoralis infeksiyonu. Flora 1998; 3: 263-6.

11. Robinson RD, Lindo JF, Neva FA, Gam AA, Vogel P, Terry SI, et al. Immunoepidemiologic Studies of Strongyloides stercoralis and Human T Lymphotropic Virus Type I Infections in Jamaica. J Infect Dis.1994; 169: 692-6. [CrossRef]

12. Altintop L, Cakar B, Hokelek M, Bektas A, Yildiz L, Karaoglanoglu M. Strongyloides stercoralis hyperinfection in a patient with rheumatoid arthritis and bronchial asthma: a case report. Ann Clin Microbiol Antimicrob 2010; 9: 27. [CrossRef]

13. Turhan V, Çoban M, Öncül O, Çavuşlu Ş. Kısa Süreli Steroid Kullanan Bir Hastada Saptanan Strongyloidoz ve Loeffler Sendrom Tablosu. Türkiye Parazitoloji Dergisi 2008; 32: 48-50.

14. Moghaddam KG. Khashayar P. Hashemi M. Gastrointestinal strongyloidiasis in Immunocompromised patients: a case report. Acta Med Indones 2011; 43: 191-4.

15. Win TT. Sitiasma H. Zeehaida M. Strongyloides stercoralis induced bilateral blood stained pleural effusion in patient with recurrent Non-Hodgkin lymphoma. Trop Biomed 2011; 28: 64-7.

16. Lessnau KD, Can S, Talavera W. Disseminated Strongyloides stercoralis in human immunodeficiency virus-infected patients. Treatment failure and a review of the literature. Chest 1993; 104: 119-22. [CrossRef]

17. Keiser PB, Nutman TB. Strongyloides stercoralis in the Immunocompromised Population. Clin Microbiol Rev 2004; 17: 208-17. [CrossRef]

18. Lim S, Katz K, Krajden S, Fuksa M, Keystone JS, Kain KC. Complicated and fatal Strongyloides infection in Canadians: risk factors, diagnosis and management. CMAJ 2004; 171: 479-84. [CrossRef]

19. Newberry AM, Williams DN, Stauffer WM, Boulware DR, HendelPaterson BR, Walker PF. Strongyloides hyperinfection presenting as acute respiratory failure and gram-negative sepsis. Chest 2005; 128 : 3681-4. [CrossRef]

20. Oztürk G, Aydınlı B, Celebi F, Gürsan N. Gastric perforation caused by Strongyloides stercoralis:a case report. Ulus Travma Acil Cerrahi Derg 2011; 17: 90-2. [CrossRef]

21. Çulha G, Savaş L, Önlen Y. Kronik Diyare Yakınması Olan Bir Hastada Strongyloides stercoralis. Türkiye Parazitoloji Dergisi 2006; 30: 293-5.

22. Tamer GS, Dündar D. Kronik Karın Ağrısıyla Seyreden Strongyloidosis. Türkiye Parazitoloji Dergisi 2008; 32: 171-3. 